\title{
Erratum to: Possible Role of Trichophytin Antigen in Inducing Impaired Immunological Clearance of Fungus in Onychomycosis
}

\author{
Chhavi Gupta - Shukla Das • V. G. Ramachandran - Rumpa Saha \\ S. N. Bhattacharya $\cdot$ Sajad Ahmad Dar $\cdot$ Dharmendra Atri
}

Published online: 28 January 2016

(C) Springer Science+Business Media Dordrecht 2016

\section{Erratum to: Mycopathologia DOI 10.1007/s11046-015-9973-3}

In the initial online publication of this paper the author name Sajad Ahmad Dar was incorrectly

The online version of the original article can be found under doi:10.1007/s11046-015-9973-3.

C. Gupta $(\bowtie) \cdot$ S. Das · V. G. Ramachandran .

R. Saha · S. A. Dar · D. Atri

Department of Microbiology, University College of

Medical Sciences (UCMS) and Guru Teg Bahadur

Hospital (GTB Hospital), Dilshad Garden, Delhi 110095,

India

e-mail: chhavi13.86@gmail.com

S. Das

e-mail: shukladas_123@yahoo.com

V. G. Ramachandran

e-mail: rama_88@yahoo.com

R. Saha

e-mail: rumpachatterjee@yahoo.co.in spelled Sajad Ahmed Dar. This has now been corrected.

S. A. Dar

e-mail: darsajad990@gmail.com

S. N. Bhattacharya

Department of Dermatology, University College of Medical Sciences (UCMS) and Guru Teg Bahadur Hospital (GTB Hospital), Dilshad Garden, Delhi 110095, India

e-mail: snbhattacharya@hotmail.com

Present Address:

S. A. Dar

Women's Health Services, Henry Ford Health System, 1 Ford Place, Detroit, MI 48202, USA 